\title{
Supplier Selection in Supply Chain Based on Fuzzy Comprehensive Evaluation Method
}

\author{
Chenyang Zhang ${ }^{1}$, Zhuwu Zhu' ${ }^{1}$, Jian Liu ${ }^{1}$, Ke Zhou ${ }^{1}$ \\ ${ }^{1}$ College of Energy and Mining Engineering Shandong University of Science and Technology Qingdao, China
}

\begin{abstract}
First of all, the type of supplier under the environment of supply chain is presented, and the choice of supplier to consider factors and selection methods, and then based on the analysis of a supplier evaluation index system should follow the four principles on the basis of the proposed a supplier evaluation index system. The thought and method of fuzzy comprehensive evaluation of the evaluation of suppliers are introduced, supplier fuzzy comprehensive evaluation model is established, and the instance is given to test and verify.
\end{abstract}

\section{Introduction}

At present, with the increasing trend of global economic integration and business globalization, the competition among enterprises is becoming increasingly fierce. In this new environment, enterprises are facing more and more pressure to shorten delivery time, improve product quality, reduce costs and improve service. Faced with this pressure, from the perspective of supply chain management, enterprises should strengthen the management of suppliers, so as to reduce costs and increase profits[1]. The evaluation and selection of suppliers is the basis of supply chain cooperation. Nowadays, the performance of suppliers has more and more influence on manufacturing enterprises, such as delivery, product quality, lead time, inventory level, product design. The traditional supply relationship is no longer suitable for the environment of intensified global competition and changing product demand[2]. In order to achieve low-cost, high-quality, flexible production and rapid response, the business restructuring of enterprises must include the evaluation and selection of suppliers. There are many methods of supplier selection in enterprise supply chain, such as intuitive judgment method, bidding method, negotiation selection method, procurement cost comparison method, $\mathrm{ABC}$ classification method, analytic hierarchy process, etc. However, due to the uncertainty and fuzziness in supplier selection, there are objective reasons (fuzziness and difficulty in quantifying evaluation indexes), There are also subjective reasons (personality, preference, values and cognitive degree) of decision-makers themselves[3]. Therefore, it is of theoretical significance and practical value to introduce the idea and method of fuzzy set theory to establish the corresponding fuzzy evaluation method. This paper mainly analyzes the selection of suppliers in the current supply chain environment, and puts forward reasonable suggestions, so as to provide reference for enterprises in practice and make enterprises obtain greater economic benefits.

\section{Evaluation index of supplier selection in supply chain}

\subsection{Types of Suppliers in Supply Chain Management Environment}

Due to the need of close cooperation in supply chain, and manufacturers need to look for the most outstanding suppliers in the global market. In order to select suppliers more effectively, suppliers can be divided into different types, so as to have targeted management.

The suppliers are divided into important suppliers and secondary suppliers. The important suppliers are a small number of suppliers who have close relationship with manufacturers, while the secondary suppliers are relatively many suppliers with little relationship with manufacturers. The change of supply chain cooperation relationship mainly affects important suppliers, but has little impact on secondary suppliers[4].

In practice, different types of suppliers are selected according to different objectives. In the long run, suppliers are required to maintain high competitiveness and valueadded rate, so it is better to choose strategic suppliers; for the short-term or a short-term market demand, it is only necessary to select ordinary suppliers to meet the demand, so as to ensure the minimum cost; for the medium-term, We choose suppliers mainly considering the competitiveness and value-added rate of suppliers..

\subsection{Setting Principle of Supplier Index System}

There are many factors involved in supplier evaluation, including qualitative and quantitative ones, and the weight of each index is different[5]. Therefore, it is necessary to establish a general and extensible supplier evaluation index system, which should follow the following 
principles:

1) The principle of system comprehensiveness: The evaluation index system must fully reflect the current comprehensive level of partner enterprises, and include various indicators of enterprise development prospects.

2) Concise and scientific principle: The size of the evaluation index system must also be appropriate, not too large or too small, that is, the setting of the evaluation system should be scientific.

3) Principle of stability and comparability: The setting of evaluation index system also takes into account the comparison with other domestic index systems.

4) Principle of flexible operability: The evaluation index system should be flexible enough to enable enterprises to flexibly use the indicators according to their own characteristics and actual situation.

\subsection{Factors to Be Considered in Supplier Selection}

At present, the main standard for Chinese enterprises to choose suppliers is product quality, which is consistent with the international trend of attaching importance to quality, followed by price, which is considered by $92.4 \%$ of enterprises; Delivery lead time is considered by $69.7 \%$ of enterprises; Batch flexibility and variety diversity are also factors considered by enterprises[6].

\subsection{Evaluation Structure of Supplier Comprehensive Index System}

Supplier evaluation is complex because of its fuzziness and many factors involved. According to the three principles of supplier evaluation index system. Based on Rick dove's TCRS (time, cost, robustness, scope of change), referring to references 4 and 5 , this paper establishes a set of supplier evaluation index system through comprehensive analysis of various factors affecting suppliers. The index system includes the price of the enterprise, the flexibility of delivery, the reputation of the enterprise (including: the history of supply, reputation, service, training in the same industry), the capacity of production and technology(including: the capacity of production facilities and the technical capability), the financial status of enterprises and the advanced nature of enterprise production(including: information level, advanced technique and degree of standardization).

\section{Fuzzy comprehensive evaluation model for suppliers}

Fuzzy comprehensive evaluation method based on fuzzy mathematics. According to the theory of membership degree of fuzzy mathematics, this comprehensive evaluation method transforms qualitative evaluation into quantitative evaluation, that is to say, fuzzy mathematics is used to make a general evaluation of things or objects restricted by many factors.

The basic idea of fuzzy comprehensive evaluation method is to use the degree of belonging (membership degree) instead of belonging to or not belonging to.

\subsection{Establish Supplier Evaluation Index Set U}

Establish the object set of the evaluated object $A=$ $\left\{A_{1}, A_{2}, \cdots, A_{n}\right\}$, Factor set $\mathrm{U}=\left\{u_{1}, u_{2}, \cdots, u_{n}\right\}$, The following conditions are met:

$$
\bigcup_{I}^{n} u_{i}=U, u_{i} \cap u_{j}=\emptyset, i \neq j, n=7
$$

\subsection{Set Up Comment Set V and Score Set F}

Suppose to establish a five level supplier comment set $F=$ $\left\{V_{1}, V_{2}, \cdots, V_{5}\right\}=\{$ very good, good, average, poor, very poor $\}$, Corresponding score $F=\{1,0.8,0.6,0.4,0.2\}$.

\subsection{Determine Index Weight Set W}

The methods to determine the weight include Delphi method, weighted average method, expert survey method and solving fuzzy relation equation method. The analytic hierarchy process (AHP) and grey correlation degree are used to construct the weight matrix of comparative judgment.

$$
\begin{aligned}
& W=\left(w_{1}, w_{21}, \cdots, w_{n}\right) \\
& W_{i}=\left(w_{i 1}, w_{i 2}, \cdots, w_{i m}\right) \\
& i=(4,5,6,7), w_{\mathrm{ij}} \text { is the weight of } U_{\mathrm{ij}} \text { in } U_{i}, \mathrm{~m} \text { is }
\end{aligned}
$$
the number of secondary indicators of $U_{i}$.

\section{$3.4 u_{i}$ Is Evaluated by Fuzzy Comprehensive Evaluation}

The fuzzy evaluation matrix $R_{i}$ can be obtained by evaluating each factor of $U_{i}$.

$$
R_{i}=\left(\begin{array}{cccc}
r_{i 11} & r_{i 12} & \ldots & r_{i 1 k} \\
r_{i 21} & r_{i 22} & \ldots & r_{i 2 k} \\
\vdots & \vdots & \vdots & \vdots \\
r_{i m 1} & r_{i m 2} & \ldots & r_{i m k}
\end{array}\right)
$$

\subsection{Comprehensive Evaluation of $u_{i}$}

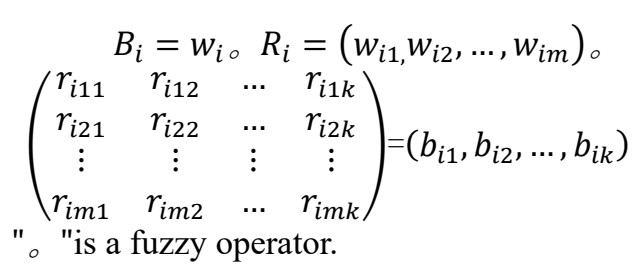

\subsection{Fuzzy Comprehensive Evaluation of U}

Select fuzzy operator:

$$
b_{j}=\sum_{i=1}^{m}\left(w_{i j} \cdot r_{i j}\right), j=1,2, \cdots k
$$

Determine the total evaluation matrix $R^{\prime}$, $R^{\prime}=\left(B_{1}, B_{2}, \cdots, B_{n}\right)^{T}$

The evaluation result is a fuzzy comprehensive evaluation set on object set $\mathrm{A}$ :

$$
\mathrm{B}=\mathrm{W}^{\circ} R^{\prime}=\left(b_{1}, b_{2}, \cdots, b_{m}\right)
$$

According to the supplier's comprehensive score ranking, select the supplier. 


\section{Model application}

An automobile manufacturer has to purchase a certain raw material among four raw material suppliers (A1, A2, A3, A4), The indicators of the four units are shown in the table below:

Table1. Quotation, quality and other indicators of 4 enterprises

\begin{tabular}{ccccc}
\hline Enterprise & quality & Delivery flexibility & Price & Financial situation \\
\hline A1 & average & average & good & very good \\
A2 & good & average & good & average \\
A3 & good & very good & average & very good \\
A4 & average & good & average & good \\
\hline
\end{tabular}

\subsection{Determine Supplier Evaluation Index Set}

$$
\begin{aligned}
& U=\left(u_{1}, u_{2}, \cdots u_{7}\right) ; u_{4}=\left(u_{41}, u_{42}, u_{43}, u_{44}\right) ; u_{5}= \\
& \left(u_{51}, u_{52}\right) ; u_{7}=\left(u_{71}, u_{72}, u_{73}\right) .
\end{aligned}
$$

Table2. Comparison of enterprise reputation of four enterprises

\begin{tabular}{ccccc}
\hline \multirow{2}{*}{ Enterprise } & Supply records & Industry reputation & Service & Train \\
\hline A1 & good & average & very good & good \\
A2 & good & good & good & average \\
A3 & good & very good & good & very good \\
A4 & good & very good & & very good \\
\hline
\end{tabular}

Table3. Comparison of production and technical capabilities of four enterprises

\begin{tabular}{ccc}
\hline Enterprise & Capacity of production facilities & Technical capability \\
\hline A1 & very good & good \\
A2 & average & good \\
A3 & good & very good \\
A4 & very good & good \\
\hline
\end{tabular}

Table4. Comparison of advanced production between 4 enterprises

\begin{tabular}{cccc}
\hline Enterprise & Information level & $\begin{array}{l}\text { Advanced } \\
\text { technique }\end{array}$ & Degree of standardization \\
\hline A1 & average & average & good \\
A2 & average & average & good \\
A3 & good & good & good \\
A4 & good & good & very good \\
\hline
\end{tabular}

\subsection{Determine The Weight of Each Index W}

Using analytic hierarchy process to calculate the weight of evaluation index is as follows:

$$
\mathrm{W}=(0.246,0.220,0.235,0.100,0.054,0.067,0.078) ; w_{4}=(
$$
$0.310,0.210,0.280,0.200) ; w_{5}=(0.540,0.460) ; w_{7}=(0.400$, $0.280,0.320)$.

\subsection{Construct Evaluation Matrix R}

Consider quality: $R_{1}=(0.600,0.800,0.800,0.600)$

Consider delivery flexibility: $R_{2}=(0.600,0.600,1.000,0.800)$

Consider price:
$R_{3}=(0.800,0.800,0.600,0.600)$

Consider corporate reputation:

$$
R_{4}=\left[\begin{array}{llll}
0.800 & 0.800 & 0.800 & 0.800 \\
0.600 & 0.800 & 1.000 & 1.000 \\
1.000 & 0.600 & 0.600 & 0.800 \\
0.800 & 0.600 & 1.000 & 1.000
\end{array}\right]
$$

Consider Production and technical capacity:

$$
R_{5}=\left[\begin{array}{llll}
1.000 & 0.600 & 0.800 & 1.000 \\
0.800 & 0.800 & 1.000 & 0.800
\end{array}\right]
$$

Consider financial situation:

$$
R_{6}=\left[\begin{array}{llll}
1.000 & 0.600 & 1.000 & 0.800
\end{array}\right]
$$

Considering the advanced nature of enterprise production:

$$
R_{7}=\left[\begin{array}{llll}
0.600 & 0.600 & 0.800 & 0.800 \\
0.600 & 0.600 & 0.800 & 0.800 \\
0.800 & 0.800 & 0.800 & 1.000
\end{array}\right]
$$




\subsection{Fuzzy Comprehensive Evaluation of $U$}

$$
\begin{aligned}
& B_{1}=R_{1} \\
& B_{2}=R_{2} \\
& B_{3}=R_{3} \\
& B_{4}=w_{4}{ }^{\circ} R_{4} \\
& B_{5}=w_{5}{ }^{\circ} R_{5} \\
& B_{6}=R_{6} \\
& B_{7}=w_{7} R_{7} \\
& R^{\prime}=\left[B_{1}, B_{2}, \cdots, B_{7}\right]^{T}=\left[\begin{array}{llll}
0.600 & 0.800 & 0.800 & 0.600 \\
0.600 & 0.600 & 1.000 & 0.800 \\
0.800 & 0.800 & 0.600 & 0.600 \\
0.786 & 0.704 & 0.785 & 0.841 \\
0.854 & 0.692 & 0.849 & 0.854 \\
1.000 & 0.600 & 1.000 & 0.800 \\
0.664 & 0.664 & 0.800 & 0.832
\end{array}\right] \\
& \mathrm{B}=\mathrm{w}^{\circ} R^{\prime}=(0.697,0.709,0.773,0.747) \\
& B^{\prime}=(0.238,0.243,0.264,0.255)
\end{aligned}
$$

\subsection{Conclusion}

The suppliers are ranked as follows: $A_{3}>A_{4}>A_{2}>A_{1}$, so we choose $\mathrm{A} 3$ as the supplier.

\section{5 conclusion}

This paper puts forward the general principles that the supplier evaluation index system should follow, and establishes the supplier evaluation index system on the basis of this principle. In practical application, the index system is modified and supplemented for specific enterprises or specific industries. The introduction of fuzzy set theory into supplier selection is conducive to the quantification of qualitative indicators and reduces the subjectivity in traditional supplier evaluation.

\section{References}

1. Li N, Li J G. Study on the Choice of Logistics Supplier in Wind Power Manufactures Based on Fuzzy Comprehensive Evaluation[J]. Advanced Materials Research, 2014, 945-949:2830-2833.

2. Ofluolu P, Rk N, Mutlu M M. The best supplier selection by using analytic hierarchy process (AHP) and fuzzy comprehensive evaluation (FCE) methods: An example of a Turkish leather apparel company[J]. Tekstil ve Konfeksiyon, 2017, 27(4):326-333.

3. Wu T H, Chen C H, Mao N. Fishmeal Supplier Evaluation and Selection for Aquaculture Enterprise Sustainability with a Fuzzy MCDM Approach[J]. Symmetry, 2017, 9(12):286.

4. Guo Z, Liu H, Zhang D. Green Supplier Evaluation and Selection in Apparel Manufacturing Using a Fuzzy Multi-Criteria Decision-Making Approach[J]. Sustainability, 2017, 9(4).

5. Yu Z, Jin H. Evaluation of military fresh food cold chain logistics suppliers based on fuzzy analytical hierarchy process[J]. Journal of Food Safety \& Quality, 2019.
6. Guan J, Zhang Z H, Wu Y. Using Fuzzy MatterElement Model and Triangular Fuzzy AHP Method to Select the International Construction Project Material Suppliers[J]. Applied Mechanics \& Materials, 2013, 357-360:2277-228. 